\title{
The Research on the Industrialization Modes of Gymnasiums in Universities and Colleges
}

\author{
YU Fengquan \\ Nantong University, Nantong, China
}

\begin{abstract}
At present, the social economy is developing with an accelerating speed, which also promotes the further construction of gymnasiums in universities and colleges. However, the construction of gymnasiums is in a transitional stage and it is still faced with serious challenges and brand new tasks. As a result, it is necessary to improve the management and operation mode and make it develop in the direction of market-oriented economy to better promote the overall construction of gymnasiums in universities and colleges. As it has been found in practical researches that what is the most important point is that scientific and reasonable management methods should be adopted to improve the management level of gymnasiums and facilities so that the gymnasiums' function of diversity service can be brought into full play and the value of gymnasiums can be realized and the industrialization of their management and operation can be promoted if the construction of gymnasiums in universities and colleges is going to be realized and a brand new sports center is to be formed by integrating teaching and fitness with sport industry.
\end{abstract}

Keywords: colleges and universities, gymnasiums, industrialization modes, researches

As is known to all that the uppermost function of gymnasiums in universities and colleges is carrying out physical education, but services, such as sports competitions, sports training, and extracurricular sports activities are the management and practical basis in the course of construction. With the development of social economy and the changes of people's lifestyle and minds, the potential of gymnasiums in universities and colleges has been excavated and exploited deeply on the basis of that and arrangements have been made according to the characteristics of specific sporting events to allocate resources reasonably. What is more, the gymnasiums have been accessible to all people whether they are from the schools or not. It has been seen that the prominent prerequisite of fulfiling the sports task of universities and colleges to construct the gymnasiums in universities and colleges and to use and manage them reasonably in the course of physical education. As the important resource of sports industry in universities and colleges, the adaptability of gymnasiums to the new social environment and the practices in the course of the sharing of educational resource are of great significance.

YU Fengquan, Dr., lecturer, Institute of Sports Science, Nantong University. 


\section{The Analysis of the Factors Influencing the Industrialized Operation of Gymnasiums of Universities and Colleges}

\section{The Economic Condition}

In terms of capital investment, colleges and universities make limited capital investment in sports construction and the investment is even as little as thousands of yuan, but these gaps and subordinations are directly related to the scale of the universities and colleges. If the universities and colleges are of large scale, then the funds invested will increase accordingly, and if there are more than ten thousands of students and teachers in a university, there must be some advantages in investing capital in sports (Li, 2015). And this kind of relationship is exactly in accordance with the need of universities and colleges, because if a university is of large scale, it is natural that the number of teachers and students is large. So, the uppermost premise of guaranteeing the smooth operation of teaching profession is the possession of adequate investment. Generally speaking, large colleges and universities are key institutions, consequently, priorities are always given to them in terms of investment. After the deep analysis and studies of the utilization of gymnasiums with different investment in colleges and universities, it has been found that the larger the investment of gymnasiums is, the higher compensable opening rate is.

In terms of the construction project of gymnasiums, given that social economy and educational career are developing in an increasingly speed, universities and colleges have attached great importance to the improvement of the school environment and the construction of gymnasiums has been taken into consideration. Many universities and colleges have made the construction plan of new gymnasiums. If industrialized economy of universities and colleges is perfect, it will be easier for people to realize the influences that the conditions of gymnasiums have on economic benefits. At the same time, gymnasiums will gain optimal investment income under the market economy condition with more plans of reconstruction and new construction.

\section{Material Conditions}

There are great differences between different universities and colleges in terms of subordination, types and even the scale and location, and the scale of universities has some influences on the utilization of resources of gymnasiums. The larger the scale is, the higher the opening rate is, and then the extent of the operation of its industrialization is further deepened $(\mathrm{Xu}, 2014)$. From the perspective of the conditions of gymnasiums, the number of the indoor and outdoor gymnasiums in universities and colleges will exert great influences on the rate of operation of their industrialization. Especially for the indoor gymnasiums, with their level higher than that of outdoor gymnasiums in various aspects, such as investment, service level, and level, their benefits will be more ideal in the course of industrialized operation. Therefore, the resource condition of gymnasiums themselves are of great importance, because that will affect the extent of industrialized operation of gymnasiums directly.

\section{Ideas and Consciousness}

The leaders' ideas and consciousness are of key importance in the process of the industrialized operation of gymnasiums in universities and colleges. Especially for the relationship between "guaranteeing the order of the campus" and "gymnasiums' serving of the whole society," if it can be dealt with in a reasonable and proper way, the operational effectiveness of gymnasiums is bound to be strengthened (Xia, 2014). So, it can be seen that leaders of universities and colleges should transform their ideas actively and make arrangement reasonably, and only in this way can the compensable opening of gymnasiums be better realized. Besides, the consciousness 
of the leaders and staffs in the sports department also plays a prominent role in the course of the industrialized operation of gymnasiums in universities and colleges.

\section{The Construction of High-Level Sports Teams}

The key of realizing the construction of high-level sports teams is taking optimal conditions of gymnasiums as the support. Generally speaking, if the level of the sports teams of universities and colleges is relatively high, the condition of gymnasiums is inevitably superior to that of common universities and colleges and thus the operational condition of industrialization is relatively mature. At the same time, with high-level sports teams, their different sports events will affect the paid operation of gymnasiums in a positive way. Because the condition of gymnasiums provides advantageous conditions for the carrying out of different sports events, it also contributes to the industrialized operation of gymnasiums (Pan, Xia, \& Li, 2012).

\section{The Construction of the Administrative Rules of Gymnasiums}

The competent department of gymnasiums in colleges and universities is the soft environment element of their resource management. As a result, the key to manage gymnasiums in a better way is the construction of rules and regulations. However, there are many issues in the construction of rules and regulations of gymnasiums in colleges and universities at the present stage and it is difficult to develop and make use of the resources of gymnasiums fully. Consequently, rules and regulations of the resource management of gymnasiums need to be improved actively to lay a solid foundation for the industrialized operation of gymnasiums in colleges and universities.

\section{Problems in the Industrialization of Gymnasiums in Colleges and Universities}

\section{The Number of Gymnasiums Is Limited}

At present, the most significant problem in the process of the industrialization of gymnasiums in colleges and universities is that the number of gymnasiums is inadequate. And compared with the developed countries, the overall quality of gymnasiums in colleges and universities in China if not enough. It can be seen from this that though the overall development level of gymnasiums in colleges and universities in China is in an ideal state, there is still a large gap compared with that of developed countries. Besides, there are still obvious differences in terms of the overall area and the level of equipment and devices. The devices and equipment of gymnasiums in colleges and universities are so simple that a lot of sports events cannot be carried out because of the lack of equipment and devices.

\section{The Marketization Degree Is Not High and Resource Utilization Rate Is Limited}

In the process of the industrialization of the gymnasiums in colleges and universities, the marketization degree is not high and resource utilization rate is limited. It has been influenced by the long-term planned economic system, even the reform and opening up policy has been implemented in the round and the economic system has been fully reformed, the influences of the planned economic system still exist and are hard to be repelled (Yang, 2012). What is more, most universities and colleges are ran by the government in China, so the government has certain power over the activities of colleges and universities. However, in this condition, the government will ignore the issue of the masses' utilization of gymnasiums when using and allocating gymnasiums in colleges and universities, which causes that gymnasiums open to the public nominally and are lack of openness in essence. In addition, the methods of gymnasiums in colleges and universities are not flexible enough when they are dealing with the problem of market. As a result, the utilization efficiency of resources is not high. 


\section{The Uneven Distribution of Resources}

It is obvious that there are more universities and colleges in the eastern part than the western part in our country, which is also the prominent reason why the distribution of the resources of gymnasiums of colleges and universities is uneven (Yang, 2011). Nevertheless, in the Western region in China, the economic development level is not high, the resources that universities and colleges can utilize are not much enough. And the distribution of the number of universities and colleges is also uneven in the eastern area.

In addition, there are still some differences in the sports resources of the same university and the distribution of resources is not even, which is shown specifically in that the sports resources in the old campus lag behind those in the new campus for the same university and the main reason is that universities tend to plan the area of the gymnasium in the course of constructing the new campus (Du, Liu, \& Wang, 2011). And because the gymnasium always covers a large area, the new campus of universities and colleges usually occupies much land and the new campus always locate in the suburb and is far from the places where people live. And it is because of this that many people do not go to the suburbs because of exercises, which influences the development of the industrialization of gymnasiums. Though the sports resources in the new campus are limited, the real utilization rate is not high and the extent of public attention is relatively low, which causes the problems in the industrialization of gymnasiums in colleges and universities.

\section{Universities and Colleges Have Insufficient Funds and Cannot Afford the Later Maintenance}

A large amount of funds are needed in the later maintenance of gymnasiums in universities and colleges, but the funds that universities and colleges possess are insufficient. At the present stage, the authentic operation in the management system of universities and colleges is smack of the administrative color, so most of the funds of the construction and operation of them are granted by the government (Guo, 2015). With the quality of people' life has been improved obviously, the requirements of gymnasiums, especially the needs of the number and quality of gymnasiums, are also increased gradually. Under this condition, it is absolutely not enough to construct gymnasiums by solely depending on government grants and it is indispensable to have more financial support to guarantee the normal operation of gymnasiums and conduct the maintenance actively.

\section{The Management System Lags Behind and the Loss Is Great}

At present, the staffs who are in charge of the management of gymnasiums have never received professional training and they are lack of relevant professional knowledge. Besides, in the opening process of gymnasiums, the service contents and management methods in most universities and colleges are not united, which causes the operation and management in a mess ultimately (Yin \& Wang, 2014). And the modes of management and operation of gymnasiums are not scientific enough, so it is hard to attract the sports consumption of the public, which gives rise to problems, such as the unreasonable allocation, losses, and wastes come into being. At the same time, it is common that many people taking do exercises always feel the conflicts between the supply and the demand, which not only causes severe wastes, but also restrict the full implementation of the nationwide physical fitness plan.

\section{Specific Ways Of Improving the Mode of Industrialization of Gymnasiums in Colleges and Universities}

Because most sports infrastructure constructions are public sports facilities paid and built by the government, they bear the responsibility endowed by the government and their characteristic of social publicity is obvious. Nevertheless, this also determines that it is hard for sports infrastructure constructions transform into business units with self-development and self-management. The modernization of the management of 
sports facilities in universities and colleges is the relevant target that is to be realized by applying market means. It will be taken as the important tenets that the utilization rate should be improved and gymnasiums should serve the society to realize the industrialization of gymnasiums and improve the utilization rate of talents so that the needs of students and the public can be satisfied and the economic and social benefits of gymnasiums can be improved.

\section{Realizing the Paid Openness to the Society and the Marketization of Sports Resources}

Universities and colleges are important parts of the society and their major functions are cultivating high-quality talents for the society, better providing services for the society, undertaking social responsibilities, and carrying out relevant obligations. As a result, gymnasiums in colleges and universities should open to the public. As it has been explicitly stipulated in Regulations of Public Cultural and Sports Facilities issued by the State Council that the government should award government institutions and schools and make cultural and sports facilities open to the public and make sure that the administrative units of public cultural and sports facilities can provide better services by providing enough financial support. At the same time, with the incessant development of the society and the change of people's ideas, people can strengthen their physique, enrich their life, and get relaxed by exercises, which is also the salient social foundation of the paid openness of gymnasiums in colleges and universities. Therefore, gymnasiums in colleges and universities must change their traditional enclosed management modes and transform into the diversified comprehensive management modes. And the sharing of sports resources can make sure that the development of university resources and community marketing resources can satisfy the cultural and sports needs of community residents. What is more, given that the market of sports resources in universities and colleges is developed on the basis of the sharing of university resources and developed resources, hardware resources should be studied according to the software and intra-universities cooperative teaching situations to make sure that it can be in accordance with the needs of students. At the same time, social capital should be introduced actively to promote the construction of gymnasiums in colleges and universities. And because there are physical teachers - the unparalleled advantage in gymnasiums in colleges and universities, ideal economic benefits not only can be gained in the course of the marketing of sports resources of gymnasiums in colleges and universities, but also the virtuous cycle can be promoted and the sharing of sports resources in universities and colleges can be realized and the operation efficiency can be improved.

\section{Cultivating the Market in Universities and Colleges and Tapping Their Potential}

Universities are of great advantage in the course of cultivating the sports market of universities and colleges. The sports consuming groups, such as teachers and students in colleges and universities are fixed and they belong to the high-quality fitness group, and only the effectiveness of sports shown by this very group can exert its positive guiding function and promote the full implementation of the nationwide physical fitness plan.

Universities and colleges have an elegant environment and are embedded with strong cultural atmosphere, and the price charged by gymnasiums is not high, as a result, they have absolute advantages in the development of the sports industry and occupy prominent places in the competition of sports market. Consequently, administrative staffs should change their minds actively, and they should have the market and service awareness, connect with the social construction closely and get to know the needs of sports consumption to make full use of the resources and expand the channels and develop the sports industry in a better way. 


\section{Improving the Comprehensive Quality of the Staff Members to Improve the Management Level}

The management of gymnasiums is of great importance in sports management and it will the quality of service and the service time of gymnasiums directly, so universities and colleges should cultivate professional management talents and conduct trainings for management staffs. Especially, the administrators of gymnasiums should strengthen their consciousness by learning sports management theories, so that they can get to know the functions of gymnasiums and the development of sports cause and the operational regulations of the legal market and they can seize opportunities actively and strengthen their consciousness of innovation and competition continuously. At the same time, they should observe the consumption consciousness of potential consumers and expand the market actively, so that the allocation of personnel resources and information resources can be optimized and the development of the industrialization of gymnasiums in colleges and universities can be promoted in an active way.

\section{Optimizing the Socialized Property Management Mode of the Logistics Comprehensively}

At present, in terms of the socialized management of the logistics in universities and colleges, gymnasiums with property management companies have explicit professional divisions and strong competition awareness. And service efficiency is improved by the improved service modes, so that the service time of gymnasiums are extended to their utilization functions can be fully used of and the clean, civilized, safe, and comfortable environment is created and the social and environmental benefits get improved in this way. Because gymnasiums in colleges and universities belong to special property management projects, the management rules should be explored and regulated and the property management of gymnasiums in universities and colleges should be improved and optimized fully on the basis of the differences between gymnasiums in universities and colleges and public gymnasiums to make sure that their development is adjusted with market disciplines. At the same time, the property management of gymnasiums in universities and colleges should adapt to the management mode of sports and meet the specific needs of the sports teaching system in universities and colleges to improve the functions of the gymnasiums in universities and colleges effectively.

\section{Conclusion}

To conclude, the sustainable development of sports management in universities and colleges needs the guarantee of the industrialization gymnasiums. Consequently, the management mode of gymnasiums should be explored and optimized to realize the modern management of gymnasiums by developing and utilizing the advantages of available resources and taking the characteristics of gymnasiums into consideration. At the same time, gymnasiums in universities and colleges should excavate the functions of sports facilities and give full play to their functions and value to make sure the good integration between universities and colleges and the society and realize mutual benefits.

\section{References}

Du, L., Liu, Y. E., \& Wang, H. (2011). The exploration of the theories of the industrialization of gymnasiums in universities and colleges. The Academic Journal of He Fei College (Natural Science), 21(1), 93-96.

Guo, P. F. (2015). The analysis of the plight faced by the industrialized development of gymnasiums in universities and colleges. Chinese Science \& Technology, (2), 205-207.

Li, N. N. (2015). The analysis of the problems faced by the industrialization of gymnasiums in universities and colleges. Time Education, (15), 129. 
Pan, Y. W., Xia, F., \& Li, Y. L. (2012). The research on the industrialized development of public gymnasiums in China. Knowledge Economy, (16), 111-113.

Xia, Z. Q. (2014). The research on the development of the industrialized operation and management of gymnasiums in universities and colleges in Shanghai. Contemporary Sports Technology, 4(25), 4-5 \& 7.

$\mathrm{Xu}$, H. (2014). The analysis of the industrialization mode of gymnasiums in universities and colleges. Read, Write and Calculate (Education and Teaching Research), (40), 301-302.

Yang, Y. F. (2011). The research on the strategies of the industrialized management and operation of gymnasiums in universities and colleges under the market mechanism. The Academic Journal of Jia Mu Si Educational College, (6), 221-222.

Yang, Y. F. (2014). The discussion of the industrialized operation mode of gymnasiums in universities and colleges. Contemporary Sports Technology, 2(14), 68-70.

Yin, X. L., \& Wang, Z. H. (2014). The research on the strategies of the industrialized development of large-scale public gymnasiums. Contemporary Sports Technology, 4(6), 164-165. 